OPEN ACCESS

Edited by: Annalisa Del Prete,

University of Brescia, Italy

Reviewed by:

Christoph Baerwald,

Leipzig University, Germany

Nicolas Riteau,

UMR7355 Immunologie et Neurogénétique Expérimentales et

Moléculaires (INEM), France

*Correspondence:

Pascale Jeannin

pascale.jeannin@univ-angers.fr

Specialty section:

This article was submitted to Cytokines and Soluble Mediators in Immunity, a section of the journal

Frontiers in Immunology

Received: 02 February 2021 Accepted: 04 May 2021 Published: 14 May 2021

Citation:

Brilland B, Bach-Bunner M, Gomes CN, Larochette $V$, Foucher E, Plaisance M, Saulnier $P$ Costedoat-Chalumeau N, Ghillani $P$, Belizna C, Delneste Y, Augusto J-F and Jeannin $P$ (2021) Serum Interleukin-26 Is a New Biomarker for

Disease Activity Assessment in Systemic Lupus Erythematosus.

Front. Immunol. 12:663192. doi: 10.3389/fimmu.2021.663192

\section{Serum Interleukin-26 Is a New Biomarker for Disease Activity Assessment in Systemic Lupus Erythematosus}

Benoit Brilland ${ }^{1,2}$, Maxime Bach-Bunner ${ }^{3}$, Christopher Nunes Gomes ${ }^{4}$, Vincent Larochette ${ }^{2}$, Etienne Foucher ${ }^{2}$, Marc Plaisance ${ }^{5}$, Patrick Saulnier ${ }^{6,7}$, Nathalie Costedoat-Chalumeau ${ }^{8}$, Pascale Ghillani ${ }^{8}$, Cristina Belizna ${ }^{3,9}$, Yves Delneste ${ }^{2,10}$, Jean-François Augusto ${ }^{1,2}$ and Pascale Jeannin ${ }^{2,10^{*}}$ on behalf of the PLUS group

${ }^{1} \mathrm{CHU}$ Angers, Service de Néphrologie-Dialyse-Transplantation, Angers, France, ${ }^{2}$ Univ Angers, CHU Angers, INSERM, CRCINA, Angers, France, ${ }^{3} \mathrm{CHU}$ Angers, Service de Médecine interne, Angers, France, ${ }^{4} \mathrm{CHU}$ Angers, Service des Maladies du sang, Angers, France, 5 Service de Pharmacologie et d'Immunoanalyse, Commissariat à l'Energie Atomique Saclay, iBiTec-S, Gif sur Yvette, France, 6 Univ Angers, INSERM, CNRS, MINT, Angers, France, ${ }^{7} \mathrm{CHU}$ Angers, Département de BioStatistiques et de Méthodologie, Angers, France, ${ }^{8}$ Internal Medicine Department, Referral Center for Rare Autoimmune and Systemic Diseases, Hospital Cochin, Paris, France, ${ }^{9}$ Univ Angers, INSERM, CNRS, MitoVasc, Angers, France, ${ }^{10} \mathrm{CHU}$ Angers, Service d'Immunologie et Allergologie, Angers, France

Objective: Interleukin-26 (IL-26) has a unique ability to activate innate immune cells due to its binding to circulating double-stranded DNA. High levels of IL-26 have been reported in patients with chronic inflammation. We aimed to investigate IL-26 levels in patients with systemic lupus erythematosus (SLE).

Methods: IL-26 serum levels were quantified by ELISA for 47 healthy controls and 109 SLE patients previously enrolled in the PLUS study. Performance of IL-26 levels and classical markers (autoantibodies or complement consumption) to identify an active SLE disease (SLE disease activity index (SLEDAl) score > 4) were compared.

Results: IL-26 levels were significantly higher in SLE patients than in controls $(4.04 \pm$ 11.66 and $0.74 \pm 2.02 \mathrm{ng} / \mathrm{mL} ; \mathrm{p}=0.005)$. IL-26 levels were also significantly higher in patients with active disease than those with inactive disease (33.08 $\pm 21.06 \mathrm{vs} 1.10 \pm 3.80$ $\mathrm{ng} / \mathrm{mL}, \mathrm{p}<0.0001)$. IL-26 levels correlated with SLEDAI score and the urine protein to creatinine ratio (UPCR) $(p<0.001)$. Patients with high IL-26 levels had higher SLEDAl score, anti-DNA antibodies levels, and uPCR $(p<0.05)$. They presented more frequently with C3 or C4 complement consumption. Lastly, IL-26 showed stronger performance than classical markers (complement consumption or autoantibodies) for active disease identification.

Conclusions: Our results suggest that, in addition to classical SLE serological markers, the measurement of IL-26 levels may be a useful biomarker for active disease identification in SLE patients.

Keywords: IL-26, SLEDAI, Proteinuria, anti-DNA antibodies, complement consumption, systemic lupus erythematosus 


\section{INTRODUCTION}

Systemic lupus erythematosus (SLE) is a systemic autoimmune disease associated with the presence of autoantibodies and the formation of immune complexes that cause tissue damage (mainly targeting the skin, kidneys, and brain). Autoantibodies directed against double-stranded (ds) DNA play a key role in the initiation and maintenance of inflammatory lesions in SLE (1). Such autoantibodies were the first identified DNA shuttling molecules allowing extracellular DNA (i.e. released by dying cells) to be internalized via the Fc $\gamma \mathrm{R}$ and processed by antigenpresenting cells (APCs). The activation of APCs, which is required to initiate antigen-specific immune responses, is then induced via intracellular DNA sensors, including TLR9 (2). This process induces the production of type I interferons (IFN-I) by plasmacytoid dendritic cells (pDCs), which play a central role in the pathogenesis of lupus (3). In addition, SLE patients have elevated levels of circulating endogenous nucleic acids and of TLR9 in circulating mononuclear cells, supporting the hypothesis of a pathological role for anti-DNA autoantibodies (4). A similar DNA-shuttling activity was next reported for members of the cathelicidin family, especially LL-37. Cathelicidins are cationic and amphipathic molecules that exhibit antimicrobial activity. LL-37-mediated internalization of extracellular DNA induces the activation of several signaling pathways (TLR, STING, inflammasome) (5-7). Its ability to render extracellular DNA inflammatory has been demonstrated in several autoimmune diseases, including SLE (8). Nevertheless, anti-DNA Abs and anti-microbial peptides are not always found in SLE patients, suggesting the existence of other DNA shuttling molecules.

IL-26 was initially described as a molecule overexpressed by $\mathrm{CD}^{+} \mathrm{T}$ lymphocytes transformed by a Herpesvirus (9). This cytokine was classified in the IL-20 cytokine sub-family (10). IL26 is an amphipathic and cationic protein (calculated $\mathrm{pHi}=10.7$ ) secreted as a $36 \mathrm{kDa}$ homodimer (11) that preferentially interacts with glycosaminoglycans expressed on cell surfaces $(9,11,12)$. IL-26 was initially identified as a pro-inflammatory cytokine (11, 13 ), inducing the production of inflammatory cytokines by myeloid cells that are involved in the differentiation of naive $\mathrm{CD}^{+}{ }^{+} \mathrm{T}$ cells into Th17 cells (14). Th17 cells themselves are also a major source of IL-26 $(13,14)$, leading to an inflammatory amplification loop. Importantly, we and others have reported that, due to its biochemical characteristics, IL-26 binds to extracellular DNA and favors its internalization by monocytes and pDCs, leading to the production of IFN-I and inflammatory cytokines $(2,14-16)$.

The involvement of IL-26 in numerous chronic autoinflammatory diseases $(2,13-15,17-19)$ and in two major pathogenic processes in SLE, namely the induction of IFN-I and its production by Th17 lymphocytes, makes the analysis of its role in SLE essential. We report that the levels of IL-26 are higher in SLE patients than healthy subjects and show a significant correlation with disease activity. Thus, in addition to classical serological markers, IL-26 levels may help in SLE activity assessment.

\section{METHODS}

\section{Study Design and Clinical Diagnosis of SLE}

This study is a post-hoc analysis of the PLUS study (20), a prospective randomized, double-blind, placebo-controlled, multicenter study aiming to compare standard and adjusted hydroxychloroquine (HCQ) dosing schedules to reduce SLE flares. It was conducted from June 2007 through August 2010 in 37 French centers. Adults with a diagnosis of SLE, according to the 1997-revised American College of Rheumatology (ACR) classification criteria (21), from at least 6 months, were included. Patients had to be under stable treatment (HCQ, steroids, or an immunosuppressive regimen, such as cyclophosphamide, methotrexate, or mycophenolic acid) for at least 2 months, and to have a Safety of Estrogens in Lupus Erythematosus National Assessment SLE Disease Activity Index (SELENA-SLEDAI) $\leq 12$. The main exclusion criteria were an estimated glomerular filtration rate (eGFR, calculated from serum creatinine according to the Cockcroft-Gault equation) $<60 \mathrm{~mL} / \mathrm{min} / 1.73 \mathrm{~m}^{2}$, chronic alcoholism, and liver failure. This study followed the recommendations of the Helsinki Declaration and all participants provided written informed consent to participate.

\section{Data Analysis}

Data concerning the age, sex, SLE criteria, years since SLE diagnosis, anti-phospholipid syndrome (APS) criteria (with both clinical and laboratory criteria, as defined by the 2006 International consensus criteria (22)), SLEDAI score, creatinine, eGFR, urine protein to creatinine ratio (uPCR), antinuclear $\mathrm{Ab}$ titers assessed in a centralized manner by indirect immunofluorescence (IIF) analysis on Hep2 cells (HEp2000 slides, ImmunoConcepts, positivity set at 1/80), anti-dsDNA (Farr assay, Trinity Biotech and Eti-dsDNA, DiaSorin), C3 and C4 complement levels were collected for each SLE patient. Patients with a SLEDAI $\leq 4$ were considered to be in an inactive disease state, whereas those with a SLEDAI $>4$ were considered to be in an active disease state.

\section{IL-26 Quantification}

IL-26 was quantified in serum samples collected between 2007 and 2009 for the PLUS study. Serums were stored in $-80^{\circ} \mathrm{C}$. IL- 26 was quantified by ELISA using home-made anti-IL-26 monoclonal antibodies (mAbs), as previously described $(15,16)$. Sensitivity and specificity of this assay are detailed in Supplementary Figure 1. The detection limit is $200 \mathrm{pg} / \mathrm{ml}$. Briefly, 96-well plates (Maxisorp; Nunc) were coated with $5 \mu \mathrm{g} / \mathrm{mL}$ anti-IL-26 mAb (clone 13C9). After saturation with phosphate-buffered saline containing $5 \%$ bovine serum albumin $(\mathrm{w} / \mathrm{v})$, plates were successively incubated with the serum samples, $1 \mu \mathrm{g} / \mathrm{mL}$ biotinylated anti-IL-26 mAb (clone 8G3), and then with streptavidin-horseradish peroxidase (BD Biosciences). Bound Abs were detected using the TMB substrate (Sigma-Aldrich). The optical density was measured at $\lambda=450 \mathrm{~nm}$. IL-26 was also quantified in serum samples from 47 healthy human volunteers (Blood Collection Center, Angers, France; agreement PLER ANG 2017-01). As IL-26 can bind to circulating DNA we made sure that the latter did not interfere with IL-26 detection (Supplementary Figure 1C). 


\section{Statistical Analysis}

Subject characteristics are reported as numbers and percentages for categorical variables and as the mean \pm standard deviation or median [Inter-Quartile Range (IQR)], when appropriate, for continuous variables. Data were compared using the $\mathrm{Chi}^{2}$ test for categorical variables or Student t-test for continuous variables. For non-normal continuous variables, Mann-Whitney or Kruskal-Wallis tests (followed by Dunn post-hoc test for multiples comparisons when applicable) were used. Spearman correlation tests were used to evaluate the link between IL-26 and other parameters. Performances of markers for active SLE identification were compared using McNemar test (for sensitivities and specificities) (23) or Generalized Score Statistic (for negative and positive predictive values) (24). Statistical analyses were performed using $\mathrm{R}$ software version 3.6. P-values $<0.05$ were considered significant.

\section{RESULTS}

\section{Patients Characteristics}

Among 109 patients included in this study, 94 were female $(86.2 \%)$ and the mean age was $41.1 \pm 9.8$ years. SLE had been diagnosed an average of $12.9 \pm 7.3$ years before inclusion in the PLUS study. The mean SLEDAI score was $1.6 \pm 2.2$. As expected, given the exclusion criteria, the eGFR was $>60 \mathrm{~mL} / \mathrm{min} / 1.73 \mathrm{~m}^{2}$. These data are summarized in Table 1. Characteristics of healthy subjects (age, sex) were not available.

\section{IL-26 Levels Were Higher in Patients With SLE}

The levels of serum IL-26 were significantly higher in SLE patients than in healthy subjects $(4.04 \pm 11.66$ and $0.74 \pm 2.02$ $\mathrm{ng} / \mathrm{mL}$, respectively; $\mathrm{p}=0.005$ ) (Figure 1A). No difference in IL26 levels was observed according to the APS status $(\mathrm{p}=0.41)$ (Figure 1B). IL-26 levels were higher in patients undergoing both steroids and immunosuppressive treatment $(\mathrm{p}=0.01)$ (Figure 1C).

\section{IL-26 Levels Correlated With Disease Activity (SLEDAl) and Proteinuria}

We examined the potential relationship between SLE disease activity and IL-26 expression by comparing the IL-26 levels in patients with high (active disease, $\mathrm{n}=10$ ) or low SLEDAI score (inactive disease, $\mathrm{n}=99$ ). IL-26 levels were significantly higher in

TABLE 1 | SLE patient characteristics.

\begin{tabular}{|c|c|c|c|c|}
\hline & All cohort, $N=109$ & IL-26 “low”, N = 88 (81\%) & IL-26 "high", N = 21 (19\%) & p-value \\
\hline \multicolumn{5}{|l|}{ Baseline characteristics } \\
\hline Age & $38[33-45]$ & $38[33-46]$ & $39[33-44]$ & 0.6 \\
\hline Female sex & $94(86 \%)$ & 78 (89\%) & $16(76 \%)$ & 0.2 \\
\hline Years since SLE diagnosis & $8[5-14]$ & $7[5-13]$ & $11[10-14]$ & 0.036 \\
\hline SLEDAI & $1[0-2]$ & $0[0-2]$ & $4[4-6]$ & $<0.001$ \\
\hline SLEDAI > 4 & $10(9.2 \%)$ & $0(0 \%)$ & $10(48 \%)$ & $<0.001$ \\
\hline \multicolumn{5}{|l|}{ Biological presentation } \\
\hline Antiphospholipid syndrome & 55 (50\%) & 42 (48\%) & $13(62 \%)$ & 0.4 \\
\hline Antinuclear antibodies titer & $640[160-1280]$ & 640 [160-1280] & 640 [320-1280] & 0.16 \\
\hline Antinuclear antibodies titer (ranges) & & & & 0.09 \\
\hline $0-1 / 200$ & $29(27 \%)$ & 27 (31\%) & $2(9.5 \%)$ & \\
\hline $1 / 200-1 / 500$ & $20(18 \%)$ & $14(16 \%)$ & $6(29 \%)$ & \\
\hline$>1 / 500$ & $60(55 \%)$ & 47 (53\%) & $13(62 \%)$ & \\
\hline \multicolumn{5}{|l|}{ Anti-DNA } \\
\hline Farr assay (Ul/mL) & $6[5-16]$ & $5[5-10]$ & 17 [9-53] & $<0.001$ \\
\hline Positivity in Farr assay (> $9 \mathrm{UI} / \mathrm{mL}$ ) & $38(35 \%)$ & $23(26 \%)$ & $15(71 \%)$ & $<0.001$ \\
\hline ELISA (UI/mL) & $18[7-52]$ & $15[6-52]$ & 27 [20-55] & 0.035 \\
\hline Positivity in ELISA (> $28 \mathrm{UI} / \mathrm{mL}$ ) & $42(39 \%)$ & $32(36 \%)$ & $10(48 \%)$ & 0.5 \\
\hline \multicolumn{5}{|l|}{ Urine Protein to Creatinine ratio } \\
\hline uPCR $(g / g)$ & $0.0[0.0-0.1]$ & $0.0[0.0-0.1]$ & $0.1[0.0-0.3]$ & 0.003 \\
\hline Significant uPCR (> 0.5 g/g) & $5(4.6 \%)$ & $1(1.1 \%)$ & 4 (19\%) & 0.7 \\
\hline eGFR $\left(\mathrm{mL} / \mathrm{min} / 1.73 \mathrm{~m}^{2}\right)$ & $108[86-131]$ & $103[84-130]$ & $119[96-133]$ & 0.3 \\
\hline Creatininemia $(\mu \mathrm{mol} / \mathrm{L})$ & $65[58-73]$ & $65[58-72]$ & $66[61-80]$ & 0.5 \\
\hline \multicolumn{5}{|l|}{ Complement components } \\
\hline C3 (g/L) & $1.02[0.88-1.15]$ & $1.03[0.91-1.16]$ & $0.88[0.68-1.05]$ & 0.013 \\
\hline Low C3 levels (< 0.7 g/L) & $8(7.3 \%)$ & $2(2.3 \%)$ & $6(29 \%)$ & $<0.001$ \\
\hline C4 (g/L) & $0.19[0.15-0.24]$ & $0.19[0.16-0.24]$ & $0.16[0.11-0.24]$ & 0.2 \\
\hline Low C4 levels (< 0.15 g/L) & $26(24 \%)$ & 17 (19\%) & $9(43 \%)$ & 0.047 \\
\hline IL-26 level (ng/ml) & $0[0-0]$ & $0[0-0]$ & 12 [6-28] & $<0.001$ \\
\hline Ongoing therapy & & & & 0.12 \\
\hline None & 39 (36\%) & 34 (39\%) & $5(24 \%)$ & \\
\hline Steroids or immunosuppressive therapy & $54(50 \%)$ & $44(50 \%)$ & $10(48 \%)$ & \\
\hline Both & $16(15 \%)$ & $10(11 \%)$ & $6(29 \%)$ & \\
\hline
\end{tabular}

Data are shown as median [interquartile range] for continuous variables and as number (\%) for categorical variables.

eGFR, estimated glomerular filtration rate; SLE, systemic lupus erythematosus; SLEDAI, SLE disease activity; uPCR, urine protein to creatinine ratio.

Significant $p$-values are in bold. 

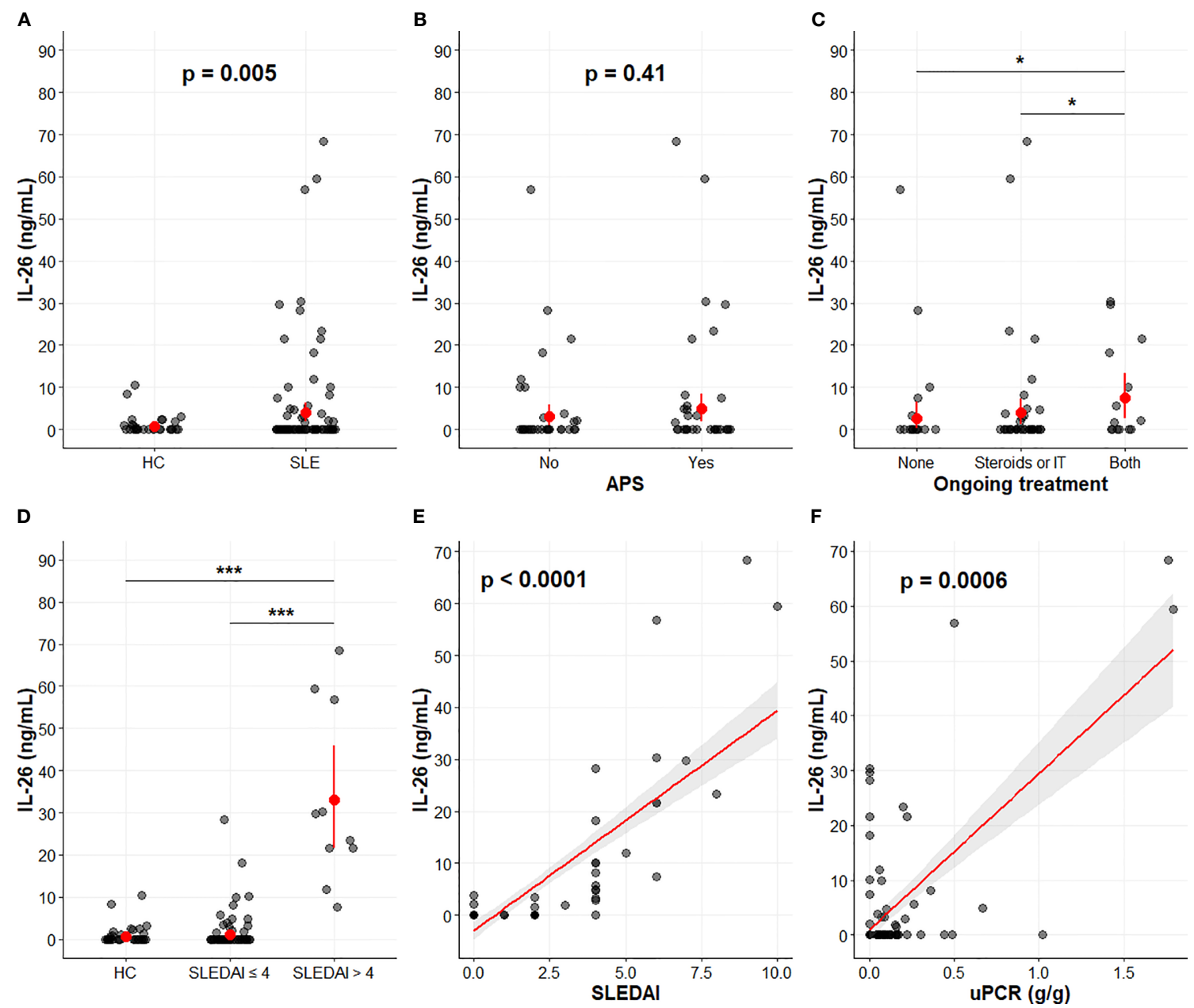

FIGURE 1 | IL-26 levels in SLE. IL-26 levels according to SLE status (A), APS status (B), and ongoing treatment (C). Correlation between IL-26 levels and SLEDAl (D, E) or the urine protein to creatinine ratio (F). (A-D) In red, mean $\pm 95 \%$ confidence interval. (E, F) Graphs depict the linear regressions (red) with the 95\% confidence intervals (grey). Spearman correlation coefficients $(\rho)$ were $0.70(p<0.0001)$ between IL-26 and SLEDAl (E) and $0.32(p=0.0006)$ between IL-26 and UPCR (F). ${ }^{*} p<0.05 .{ }^{* \star \star} \mathrm{p}<0.001$. APS, antiphospholipid syndrome; HC, healthy controls; IT, immunosuppressive therapy; SLE, systemic lupus erythematosus; SLEDAI, systemic lupus erythematosus disease activity index; UPCR, urine protein to creatinine ratio.

patients with active disease than patients with inactive disease $(33.08 \pm 21.06$ versus $1.10 \pm 3.80 \mathrm{ng} / \mathrm{mL}$, respectively; $\mathrm{p}<0.0001)$

(Figures 1D and 2A).

IL-26 levels strongly correlated with the SLEDAI $(\rho=0.70$, $\mathrm{p}<0.0001$ ) (Figure 1E) and also, to a lower extent, with uPCR $(\rho=0.32, p=0.0006)$ (Figure 1F). No correlation between IL-26 levels and creatininemia or eGFR, nor with autoantibody titers, was observed (data not shown).

\section{Patients With High IL-26 Levels Had a Higher Clinical and Serological Active Disease}

Patients with IL-26 levels higher than $3.2 \mathrm{ng} / \mathrm{mL}$ (best threshold according to area under ROC curve for SLE diagnosis) were further included in the "high IL-26 levels" (IL-26 ${ }^{\text {high }}$ ) group. Twenty-one SLE patients (19.3\%) and 2 (4.3\%) healthy controls
( $\mathrm{p}=0.015$ ) had "high" IL-26 levels. IL-26 ${ }^{\text {high }}$ patients had a disease that was significantly diagnosed longer ago $(p=0.036)$ and had a significantly higher SLEDAI score than IL-26 ${ }^{\text {low }}$ patients $(\mathrm{p}<0.001)$. In IL-26 ${ }^{\text {high }}$ patients, C3 or C4 complement component were significantly more frequently lowered $(\mathrm{p}<0.001$ and $\mathrm{p}=0.047$ respectively). Anti-DNA antibodies levels $(\mathrm{p}=0.001)$ and proteinuria were significantly higher $(p=0.003)$, while antinuclear antibodies tended to be more frequently found at higher levels $(\mathrm{p}=0.09)$. None of the IL$26^{\text {low }}$ patients had an active disease $($ SLEDAI $\leq 4)($ Table 1$)$.

\section{IL-26 Showed Stronger Performance Than Classical Markers for Active Disease Identification}

Unlike classical markers (antinuclear antibodies higher than 1/200, anti-DNA antibodies, C3 and C4 levels), which were 
A

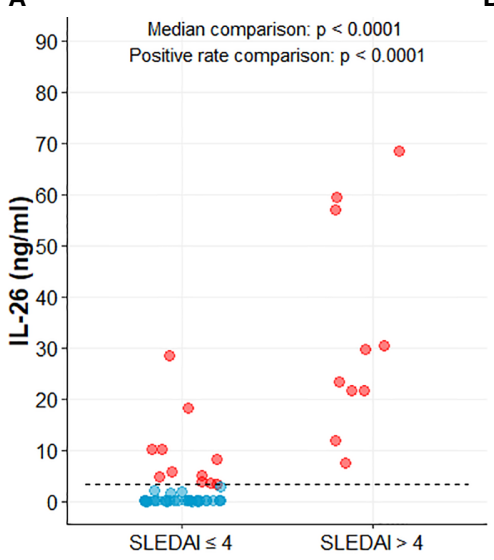

D

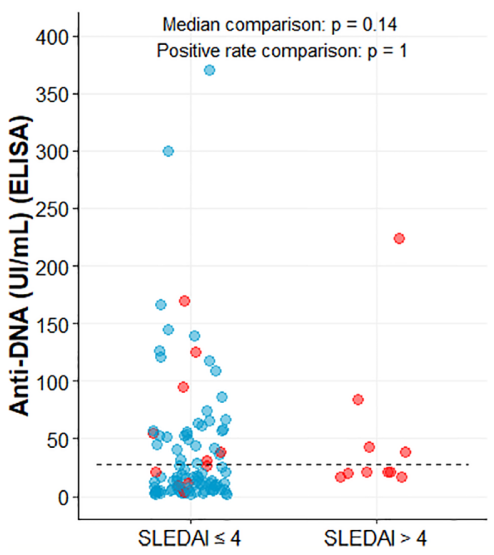

E
B
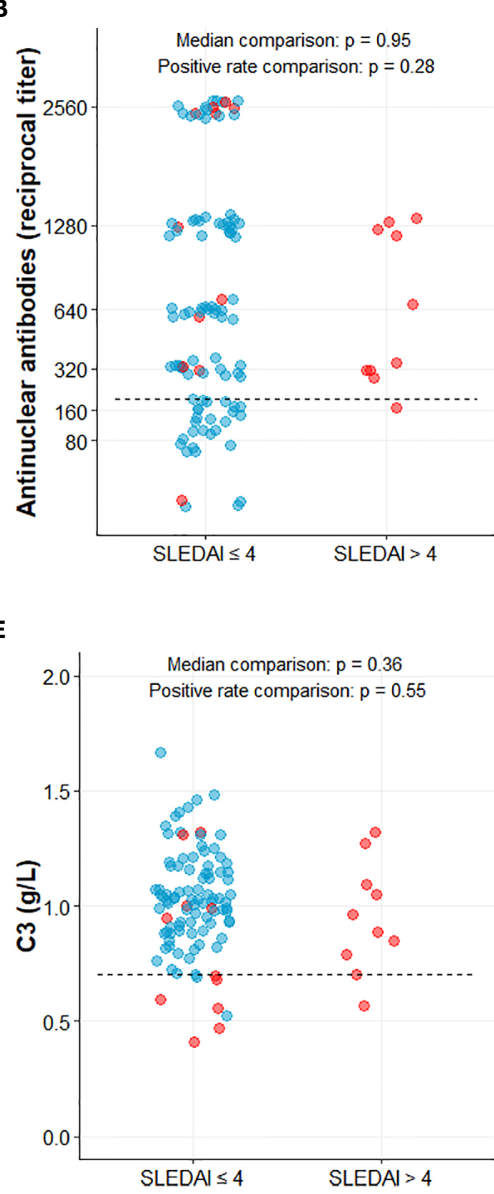

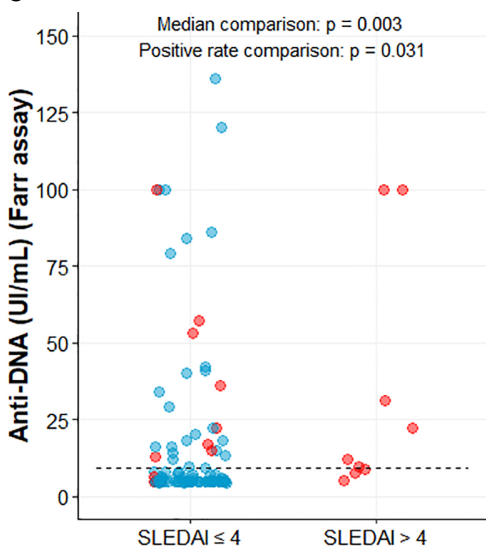

$\mathbf{F}$

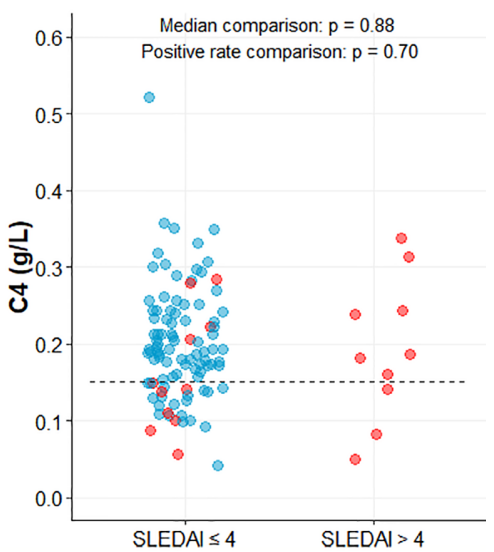

FIGURE 2 | IL-26 and classical markers according to SLE disease activity. IL-26 (A), Antinuclear antibodies (B), Anti-DNA antibodies (C, D), C3 (D) and C4 (E) complement components levels. Data were compared with Mann-Whitney test (for median comparison) and with Fisher exact test [for percentage of positive patients (above threshold)]. Dashed line represents positivity threshold, set at $3.2 \mathrm{ng} / \mathrm{ml}$ for IL-26 (A), 1/200 for antinuclear antibodies (B), $9 \mathrm{and} 28 \mathrm{Ul} / \mathrm{mL}$ for anti-DNA antibodies (Farr assay and ELISA, C and D, respectively) or lower normal value ( 0.7 and $0.15 \mathrm{~g} / \mathrm{L})$ for $\mathrm{C} 3$ and $\mathrm{C} 4$ complement component respectively (E, F). Blue and red dots represent patients in the low or high IL-26 groups respectively.

found abnormal in only a fraction of patients with an active disease (90\%, 40-70\%, $10 \%$ and 30\%, respectively), IL-26 levels were elevated in all (100\%) of them (Figure 2). Thus, elevated IL26 levels had the best performance among the classic markers for active SLE identification. Indeed, a high IL-26 level identified active SLE with similar or, in most cases, greater sensitivity, specificity, positive and negative predictive values when compared to autoantibodies (antinuclear antibodies above $1 / 200$, anti-DNA positivity) or complement consumption (Table 2).

TABLE 2 | Classical markers and IL-26 performance for active SLE identification (SLEDAI > 4).

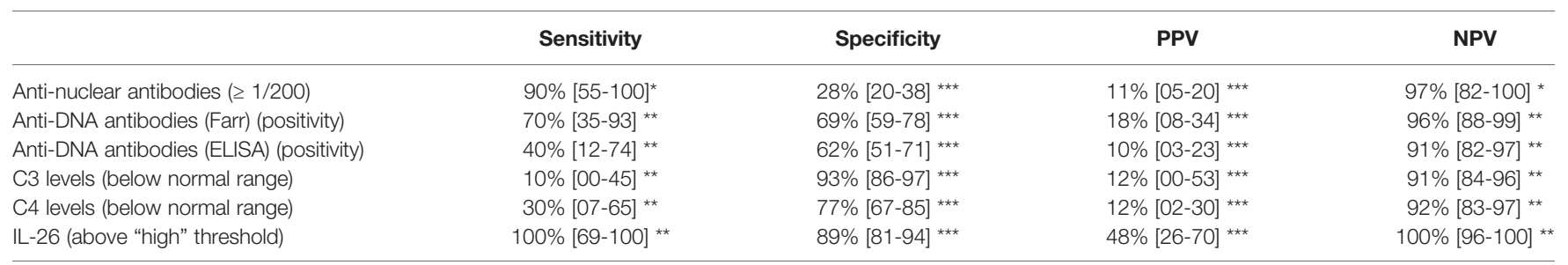

P-values of the comparison of sensitivities, specificities, PPV and NPV for each classical marker (versus IL-26) are depicted by stars $\left(^{*}<0.05,{ }^{* *}<0.01,{ }^{* * *}<0.001\right.$ ).

PPV, positive predictive value; NPV, negative predictive value. 


\section{DISCUSSION}

Here, we report that the levels of IL-26 are higher in SLE patients than in healthy subjects and that patients with active lupus have higher IL-26 levels than those with inactive disease. We found a significant correlation between IL-26 levels and disease activity (mainly with SLEDAI but also, interestingly, with uPCR despite the absence of impaired renal function, as defined in the exclusion criteria). Patients with high IL-26 levels exhibits the most active disease, both clinically and serologically. Our results underline a strong performance for IL-26 in active SLE identification in a population with known SLE and an overall low SLEDAI score.

During sterile chronic inflammation, extracellular self-DNA, probably released during episodes of massive cell death, is a major pro-inflammatory stimulus, especially in SLE patients (25). Indeed, sequestered into organites (nucleus and mitochondria) under physiological conditions, DNA can be released into the extracellular environment following accidental cell death (necrosis) or when the clearance of apoptotic cells is delayed or impaired (leading to late apoptosis/secondary necrosis). Despite the fact that extracellular DNA is recognized as a danger signal, it does not activate immune cells, mainly because DNA sensors are sequestered intracellularly and that extracellular DNA can be degraded by nucleases, unless associated with shuttling molecules allowing it to cross membranes and access intracellular DNA sensors.

IL-26 has recently emerged as a DNA-shuttling molecule involved in the pathophysiology of chronic inflammatory disorders as well as in various infectious diseases, both viral and bacterial. We report here that SLE patients, especially those with an active disease, have elevated IL-26 levels. As shown by our group and others $(2,15)$, IL-26 associates with circulating nucleic acids, protects it from nucleases, and allows their internalization into cells, where they can then interact with DNA sensors, leading to the production of IFN-I and inflammatory cytokines. This process may explain the correlation between IL-26 levels and disease activity.

Our results are in agreement with data from the literature showing that IL-26 is overexpressed in chronic inflammatory diseases. IL-26 is elevated in patients with chronic rheumatic diseases, such as rheumatoid arthritis (14), spondylarthropathies (26), or vasculitis (15), as well as Th17-mediated inflammatory skin diseases, such as psoriasis $(2,18)$ and atopic dermatitis $(27)$. Nevertheless, and contradictory to our results, a previous study reported that IL-26 levels were similar in SLE patients and in healthy subjects (28). This difference can be explained by differences in the methodologies used in these two studies. First, the SLE phenotype is different in Asian and Caucasian people due to differences in genetic susceptibility (29). Second, no information was provided on the IL-26 quantification assay used in the study by Zhang et al. This point is crucial as IL-26 quantification is rendered difficult due to its biochemical characteristics. Indeed, its high isoelectric point means that, in physiological conditions, IL-26 is positively charged and may easily bind to negatively charged surfaces, such as plastic. In this view, ELISA, including commercially assays, may underestimate and even give false negative results in fluids containing low levels of IL-26 (personal observations).

In the follow-up and monitoring of lupus patients, there are few biological parameters of interest, namely anti-dsDNA $\mathrm{Ab}$ (and/or antinuclear $\mathrm{Ab}$ ) levels, complement activity and proteinuria (without considering interferon, which is currently not routinely assayed). All of them arise late during SLE flares. In our study, and as reported in previous studies $(14,15)$, there is an overlap in IL-26 levels between patients with active and inactive disease (especially for 2 patients with an inactive disease that had high IL-26 levels). Thus, further studies on a larger cohort of clinically defined SLE patients are needed before establishing a clinically significant reference range of IL-26 levels allowing discriminating patients with inactive versus active disease. Nonetheless, our findings suggest that, in addition to standard serological assays, IL-26 may be a useful marker to monitor disease activity, even in already known SLE patients under treatment for whom classical serological markers would fail to identify an active disease. Indeed, IL-26 showed excellent sensitivity and specificity for identifying patients with an active disease, thus surpassing the classical serological markers in this purpose. Lastly, the correlation between IL-26 levels and the uPCR, even though patients with severe renal impairment were excluded, suggests that IL-26 could be useful to monitor the risk of upcoming renal injury and should be carefully investigated in further studies.

Our study had several limitations. First, given that patients with an eGFR $<60 \mathrm{~mL} / \mathrm{min} / 1.73 \mathrm{~m}^{2}$ were excluded and no longitudinal follow-up was available, we cannot draw firm conclusions concerning the risk of developing lupus nephritis. Moreover, we did not monitor IL-26 levels over time which did not allow us to evaluate its potential to predict flare. Lastly, we must keep in mind that, as C-reactive protein, erythrocyte sedimentation rate or other pro-inflammatory cytokines, IL-26 appears as a non-specific marker of inflammation, since elevated levels have been reported in several inflammatory states, whether autoimmune or infectious.

In conclusion, our findings show that SLE patients have elevated IL-26 levels that correlate with the SLEDAI score and that patients with high IL-26 levels had a higher clinical and serological active disease. Our results need to be validated in a larger prospective cohort to confirm its usefulness as an additional diagnostic tool to monitor disease activity, help guide treatment, and better assist the clinician in the management of SLE patients.

\section{DATA AVAILABILITY STATEMENT}

The raw data supporting the conclusions of this article will be made available by the authors, without undue reservation.

\section{ETHICS STATEMENT}

The studies involving human participants were reviewed and approved by Comité de Protection des Personnes St Louis 
Hospital, Paris. The patients/participants provided their written informed consent to participate in this study.

\section{THE PLUS GROUP}

Leonardo Astudillo, Cristina Belizna, Nadia Belmatoug, Olivier Benveniste, Audrey Benyamine, Holly Bezanahary, Patrick Blanco, Olivier Bletry, Bahram Bodaghi, Pierre Bourgeois, Benoît Brihaye, Emmanuel Chatelus, Nathalie CostedoatChalumeau, Richard Damade, Eric Daugas, Christian deGennes, Jean-François Delfraissy, Céline Delluc, Aurélien Delluc, Pierre Duhaut, Alain Dupuy, Isabelle Durieu, HangKorng EA, Dominique Farge, Christian Funck-Brentano, Frédérique Gandjbakhch, Justine Gellen-Dautremer, Pascale Ghillani-Dalbin, Bertrand Godeau, Cécile Goujard, Catherine Grandpeix, Claire Grange, Lamiae Grimaldi, Gaëlle GuettrotImbert, Loïc Guillevin, Eric Hachulla, Jean-Robert Harle, Julien Haroche, Pierre Hausfater, Jean Jouquan, Gilles Kaplanski, Homa Keshtmand, Mehdi Khellaf, Olivier Lambotte, David Launay, Hervé Levesque, Olivier Lidove, Eric Liozon, Kim LY, Matthieu Mahevas, Kubéraka Mariampillai, Xavier Mariette, Alexis Mathian, Karin Mazodier, Marc Michel, Nathalie Morel, Luc Mouthon, Rokiya Ngack, Jacques Ninet, Eric Oksenhendler, Jean-Luc Pellegrin, Olivier Peyr, Anne-Marie Piette, Vincent Poindron, Fabienne Roux, David Saadoun, Sabrinel Sahali, Bernadette Saint-Marcoux, Françoise Sarrot-Reynauld, Yoland Schoindre, Jérémie Sellam, Damien Sene, Jacques Serratrice, Pascal Seve, Jean Sibilia, Claude Simon, Christelle Sordet, Benjamin Terrier, Salim Trad, Jean-François Viallard, Elisabeth Vidal, Bertrand Wechsler, Pierre-Jean Weiller, Noël Zahr.

\section{AUTHOR CONTRIBUTIONS}

$\mathrm{CB}, \mathrm{YD}, \mathrm{J}-\mathrm{FA}$, and $\mathrm{PJ}$ designed the study. $\mathrm{BB}, \mathrm{CN}, \mathrm{VL}$, and $\mathrm{EF}$ carried out the experiments. $\mathrm{BB}, \mathrm{MB}-\mathrm{B}$, and $\mathrm{PS}$ analyzed the data. $\mathrm{BB}$ and $\mathrm{MB}-\mathrm{B}$ drafted the manuscript. $\mathrm{MP}, \mathrm{PG}$, and $\mathrm{NC}-\mathrm{C}$ contributed reagents/analytic tools. YD, J-FA, and PJ revised

\section{REFERENCES}

1. Pisetsky DS. Anti-DNA Antibodies - Quintessential Biomarkers of SLE. Nat Rev Rheumatol (2016) 12:102-10. doi: 10.1038/nrrheum.2015.151

2. Meller S, Di Domizio J, Voo KS, Friedrich HC, Chamilos G, Ganguly D, et al. TH17 Cells Promote Microbial Killing and Innate Immune Sensing of DNA Via Interleukin 26. Nat Immunol (2015) 16:970-9. doi: 10.1038/ni.3211

3. Blanco P, Palucka AK, Gill M, Pascual V, Banchereau J. Induction of Dendritic Cell Differentiation by IFN-alpha in Systemic Lupus Erythematosus. Science (2001) 294:1540-3. doi: 10.1126/science.1064890

4. Mahajan A, Herrmann M, Muñoz LE. Clearance Deficiency and Cell Death Pathways: A Model for the Pathogenesis of SLE. Front Immunol (2016) 7:35. doi: 10.3389/fimmu.2016.00035

5. Lande R, Gregorio J, Facchinetti V, Chatterjee B, Wang Y-H, Homey B, et al. Plasmacytoid Dendritic Cells Sense self-DNA Coupled With Antimicrobial Peptide. Nature (2007) 449:564-9. doi: 10.1038/nature06116

6. Elssner A, Duncan M, Gavrilin M, Wewers MD. A Novel P2x7 Receptor Activator, the Human Cathelicidin-Derived Peptide Ll37, Induces Il-1 the manuscript. All authors contributed to the article and approved the submitted version.

\section{FUNDING}

This study was supported by institutional grants from Inserm and the University of Angers and by a grant from the University Hospital of Angers (Project Lupix). The funders had no role in study design, data collection and analysis, decision to publish, or preparation of the manuscript. This work was realized in the context of the Laboratory of excellence Immunotherapy GraftOncology (LabEx IGO) program supported by the National Research Agency (ANR) via the investments for the future program ANR-11-LABEX-0016-01 and by the University of Angers - University Hospital of Angers joint program (3I-Impact).

\section{ACKNOWLEDGMENTS}

The authors sincerely acknowledge Pascale Pignon and Laurence Preisser for technical assistance and Dr Julie Tabiasco for helpful discussion.

\section{SUPPLEMENTARY MATERIAL}

The Supplementary Material for this article can be found online at: https://www.frontiersin.org/articles/10.3389/fimmu.2021.663192/ full\#supplementary-material

Supplementary Figure 1 | IL-26 ELISA properties. Representative standard curve of the home-made IL-26 ELISA (A), starting from $10 \mathrm{ng} / \mathrm{ml}$ and a subsequent 2-fold dilution. Specificity of the home-made IL-26 ELISA (B) obtained with cytokines belonging to the IL-10 family (IL-10, IL-19, IL-20, IL-22, IL-24, IL-26, and IL-29), and tested independently at two concentrations (5 and $50 \mathrm{ng} / \mathrm{ml}$ ) (mean \pm $\mathrm{SEM}, \mathrm{n}=2$ independent experiment). Pre-incubating IL-26 with various concentration of partially digested DNA did not interfere with IL-26 detection (C) (mean \pm SEM, $\mathrm{n}=3$ independent experiments).

Processing and Release. J Immunol (2004) 172:4987-94. doi: 10.4049/ jimmunol.172.8.4987

7. Chamilos G, Gregorio J, Meller S, Lande R, Kontoyiannis DP, Modlin RL, et al. Cytosolic Sensing of Extracellular self-DNA Transported Into Monocytes by the Antimicrobial Peptide LL37. Blood (2012) 120:3699-707. doi: 10.1182/blood-2012-01-401364

8. Kahlenberg JM, Kaplan MJ. Little Peptide, Big Effects: The Role of LL-37 in Inflammation and Autoimmune Disease. J Immunol Baltim Md 1950 (2013) 191:4895-901. doi: 10.4049/jimmunol.1302005

9. Knappe A, Hor S, Wittmann S, Fickenscher H. Induction of a Novel Cellular Homolog of Interleukin-10, AK155, by Transformation of T Lymphocytes With Herpesvirus Saimiri. J Virol (2000) 74:3881-7. doi: 10.1128/ JVI.74.8.3881-3887.2000

10. Donnelly RP, Sheikh F, Dickensheets H, Savan R, Young HA, Walter MR. Interleukin-26: An IL-10-related Cytokine Produced by Th17 Cells. Cytokine Growth Factor Rev (2010) 21:393-401. doi: 10.1016/j.cytogfr.2010.09.001

11. Hör S, Pirzer H, Dumoutier L, Bauer F, Wittmann S, Sticht H, et al. The T-cell Lymphokine interleukin-26 Targets Epithelial Cells Through the interleukin- 
20 Receptor 1 and interleukin-10 Receptor 2 Chains. J Biol Chem (2004) 279:33343-51. doi: 10.1074/jbc.M405000200

12. Braum O, Pirzer H, Fickenscher H. Interleukin-26, a Highly Cationic T-cell Cytokine Targeting Epithelial Cells. Anti-Inflamm Anti-Allergy Agents Med Chem (2012) 11:221-9. doi: 10.2174/1871523011202030221

13. Dambacher J, Beigel F, Zitzmann K, De Toni EN, Goke B, Diepolder HM, et al. The Role of the Novel Th17 Cytokine IL-26 in Intestinal Inflammation. Gut (2009) 58:1207-17. doi: 10.1136/gut.2007.130112

14. Corvaisier M, Delneste Y, Jeanvoine H, Preisser L, Blanchard S, Garo E, et al. Il-26 Is Overexpressed in Rheumatoid Arthritis and Induces Proinflammatory Cytokine Production and Th17 Cell Generation. PloS Biol (2012) 10: e1001395. doi: 10.1371/journal.pbio.1001395

15. Poli C, Augusto JF, Dauvé J, Adam C, Preisser L, Larochette V, et al. Il-26 Confers Proinflammatory Properties to Extracellular Dna. J Immunol (2017) 198:3650-61. doi: 10.4049/jimmunol.1600594

16. Miot C, Beaumont E, Duluc D, Le Guillou-Guillemette H, Preisser L, Garo E, et al. Il-26 is Overexpressed in Chronically HCV-infected Patients and Enhances TRAIL-mediated Cytotoxicity and Interferon Production by Human NK Cells. Gut (2015) 64:1466-75. doi: 10.1136/gutjnl-2013-306604

17. Lopalco G, Lucherini OM, Lopalco A, Venerito V, Fabiani C, Frediani B, et al. Cytokine Signatures in Mucocutaneous and Ocular Behçet's Disease. Front Immunol (2017) 8:200. doi: 10.3389/fimmu.2017.00200

18. Wilson NJ, Boniface K, Chan JR, McKenzie BS, Blumenschein WM, Mattson JD, et al. Development, Cytokine Profile and Function of Human Interleukin 17Producing Helper T Cells. Nat Immunol (2007) 8:950-7. doi: 10.1038/ni1497

19. Itoh T, Hatano R, Komiya E, Otsuka H, Narita Y, Aune TM, et al. Biological Effects of IL-26 on T Cell-Mediated Skin Inflammation, Including Psoriasis. J Invest Dermatol (2018) 139(4):878-89. doi: 10.1016/j.jid.2018.09.037

20. Costedoat-Chalumeau N, Galicier L, Aumaitre O, Francès C, Le Guern V, Liote F, et al. Hydroxychloroquine in Systemic Lupus Erythematosus: Results of a French Multicentre Controlled Trial (PLUS Study). Ann Rheum Dis (2013) 72:1786-92. doi: 10.1136/annrheumdis-2012-202322

21. Hochberg MC. Updating the American College of Rheumatology Revised Criteria for the Classification of Systemic Lupus Erythematosus. Arthritis Rheum (1997) 40:1725-5. doi: 10.1002/art.1780400928

22. Miyakis S, Lockshin MD, Atsumi T, Branch DW, Brey RL, Cervera R, et al. International Consensus Statement on an Update of the Classification Criteria for Definite Antiphospholipid Syndrome (APS). J Thromb Haemost JTH (2006) 4:295-306. doi: 10.1111/j.1538-7836.2006.01753.x
23. McNemar Q. Note on the Sampling Error of the Difference Between Correlated Proportions or Percentages. Psychometrika (1947) 12:153-7. doi: 10.1007/BF02295996

24. Moskowitz CS, Pepe MS. Comparing the Predictive Values of Diagnostic Tests: Sample Size and Analysis for Paired Study Designs. Clin Trials Lond Engl (2006) 3:272-9. doi: 10.1191/1740774506 cn147oa

25. Xu Y, Song Y, Chang J, Zhou X, Qi Q, Tian X, et al. High Levels of Circulating Cell-Free DNA are a Biomarker of Active SLE. Eur J Clin Invest (2018) 48: e13015. doi: 10.1111/eci.13015

26. Heftdal LD, Andersen T, Jæhger D, Woetmann A, Østgård R, Kenngott EE, et al. Synovial Cell Production of IL-26 Induces Bone Mineralization in Spondyloarthritis. J Mol Med (2017) 95:779-87. doi: 10.1007/s00109-017$1528-2$

27. Kamijo H, Miyagaki T, Hayashi Y, Akatsuka T, Watanabe-Otobe S, Oka T, et al. Increased IL-26 Expression Promotes T Helper Type 17- and T Helper Type 2-Associated Cytokine Production by Keratinocytes in Atopic Dermatitis. J Invest Dermatol (2019) 140(3):P636-44.E2. doi: 10.1016/ j.jid.2019.07.713. S0022202X19331483.

28. Zhang M, Xu W-D, Zhu Y, Wen P-F, Leng R-X, Pan H-F, et al. Serum Levels of Cytokines in Systemic Lupus Erythematosus: Association Study in a Chinese Population. Z Für Rheumatol (2014) 73:277-80. doi: 10.1007/ s00393-013-1274-y

29. Lewis MJ, Jawad AS. The Effect of Ethnicity and Genetic Ancestry on the Epidemiology, Clinical Features and Outcome of Systemic Lupus Erythematosus. Rheumatology (2016) 56(suppl_1):i67-77. doi: 10.1093/ rheumatology/kew399. kew399.

Conflict of Interest: The authors declare that the research was conducted in the absence of any commercial or financial relationships that could be construed as a potential conflict of interest.

Copyright (๑) 2021 Brilland, Bach-Bunner, Gomes, Larochette, Foucher, Plaisance, Saulnier, Costedoat-Chalumeau, Ghillani, Belizna, Delneste, Augusto and Jeannin. This is an open-access article distributed under the terms of the Creative Commons Attribution License (CC BY). The use, distribution or reproduction in other forums is permitted, provided the original author(s) and the copyright owner(s) are credited and that the original publication in this journal is cited, in accordance with accepted academic practice. No use, distribution or reproduction is permitted which does not comply with these terms. 